Full title: Health status of critically ill trauma patients

\title{
Concise title: Health status of critically ill trauma patients
}

Leanne M Aitken, RN, PhD, FRCNA

Professor of Critical Care Nursing

Research Centre for Clinical and Community Practice Innovation, Griffith University \& Princess Alexandra Hospital, Brisbane

1.aitken@griffith.edu.au

Ph. +61731767256

Fax. +61731767356

Wendy Chaboyer, RN, PhD

Director, NHMRC Centre of Research Excellence in Nursing Interventions for Hospitalised Patients, Research Centre for Clinical and Community Practice Innovation (RCCCPI), Griffith University, Gold Coast campus

Michael Schuetz, FRACS, FAOrthA, Dr med (RWTH Aachen), Dr med. Habil (HU Berlin)

Director of Trauma Service \& Professor of Trauma, Princess Alexandra Hospital and Queensland University of Technology, Brisbane

Christopher Joyce MB, ChB, PhD, FANZCA, FCICM

Director of Intensive Care, Princess Alexandra Hospital; Associate Professor, School of Medicine, University of Queensland, Brisbane 
Bonnie Macfarlane, BHSc, MPH

Senior Research Officer/ Statistical Epidemiologist, Critical Care Nursing

Princess Alexandra Hospital \& Griffith University, Brisbane, Queensland 


\section{ABSTRACT}

Aims. To describe the recovery of trauma intensive care patients up to six months post hospital discharge.

Background. Injury is a leading cause of preventable mortality and morbidity worldwide, with approximately $10 \%$ of hospitalised trauma patients being admitted to intensive care. Intensive care patients experience significant ongoing physical and psychological burden after discharge, however the patterns of recovery and the subgroups of intensive care patients who experience the greatest burden are not described.

Design. This prospective cohort study was conducted in one tertiary referral hospital in south-east Queensland, Australia.

Methods. Following ethics approval injured patients who required admission to intensive care provided consent. Participants completed questionnaires prior to hospital discharge $(n=123)$ and one $(n=93)$ and six months $(n=88)$ later. Data included demographic and socioeconomic details, pre-injury health, injury characteristics, acute care factors, post-acute factors (self-efficacy, illness perception, perceived social support and psychological status as measured by the Kessler Psychological Distress Scale [K10] and the PTSD Civilian Checklist) and health status (SF-36).

Results. All participants required ongoing support from healthcare providers in the six months after discharge from hospital and approximately half required support services such as accommodation and home modifications. Approximately $20 \%$ of participants reported post-traumatic stress symptoms while approximately half the participants reported psychological distress. Average quality of life scores were significantly below the Australian norms both one and six months post discharge. 
Conclusions. Trauma intensive care patients rely on ongoing healthcare professional and social support services. Compromised health related quality of life and psychological health persists at six months.

Relevance to clinical practice. Effective discharge planning and communication across the care continuum is essential to facilitate access to healthcare providers and other support services in the community setting.

\section{KEYWORDS}

intensive care; wounds and injuries; stress disorders, post-traumatic; health status;

self-efficacy 


\section{INTRODUCTION}

Injury is a leading cause of preventable mortality and morbidity and has been endorsed as a priority area for preventative and management interventions in multiple different countries (Australian Institute of Health and Welfare (AIHW) 2010, Hyder \& Aggarwal 2009, Peden et al. 2002). Injury represents a major cost to families, the healthcare system and society (Connelly et al. 2006, Mathers et al. 1999).

Approximately $10 \%$ of trauma patients require admission to an intensive care unit (ICU) (Dallow et al. 2011), although there are few data to confirm if this pattern of care is internationally consistent. ICU patients experience ongoing physical and psychological burden after discharge from hospital (Needham et al. 2012). Understanding the recovery patterns of ICU trauma patients will enable development of a more responsive network of care during and immediately following hospital, with the potential to minimise disability, improve recovery and reduce cost in this population.

\section{BACKGROUND}

Despite the prevalence and impact of traumatic injury, there has been limited investigation of long term recovery for this population. Recovery in this setting is influenced by many different factors that are present at the time of injury as well as during acute and post-acute care (Richmond \& Aitken 2011). In Australia, injured adults report markedly lower health status after discharge from hospital compared with the general population (Aitken et al. 2007), consistent with research in other countries such as the United States and Scandinavia (Richmond et al. 2003, Sluys et al. 2005). Studies of recovery confirm compromised quality of life (QOL) in 20-60\% 
of patients (Harris et al. 2008, Holtslag et al. 2007, Jackson et al. 2007a, Korosec Jagodic et al. 2006, Mata et al. 1996, Ringdal et al. 2009). By comparison with other ICU patients, trauma patients appear to experience a more problematic and variable recovery, reporting poorer health status and greater deterioration than surgical or medical patients (Badia et al. 2001, Niskanen et al. 1999).

Other aspects of health that have been reported as compromised in the trauma ICU population include physical function (Livingston et al. 2009), anxiety and depression (Jackson et al. 2007a, Toien et al. 2010) and post-traumatic stress disorder or its associated symptoms (Jackson et al. 2007a, O'Donnell et al. 2010, Toien et al. 2010).

Multiple factors have the potential to influence recovery in critically injured patients (Figure 1). These include demographic variables as well as both acute and post-acute components. The relationship between non-modifiable factors such as age, injury severity and location, length of ICU stay and gender (Badia et al. 2001, Harris et al. 2008, Holtslag et al. 2007, Mata et al. 1996, Ringdal et al. 2009, Toien et al. 2010), and recovery has been identified, although after controlling for these variables a large portion of variance in outcome remains. There is some evidence of a relationship between acute and early post-acute factors and long term recovery (Richmond et al. 2003, Sluys et al. 2005, Toien et al. 2010). Interventions targeted at modifying these factors could potentially improve recovery.

This ongoing longitudinal study was designed to describe recovery of trauma intensive care patients up to two years after hospital discharge and test a multifactorial model of recovery by identifying injury, acute and early post-acute factors associated 
with that recovery. In this first report we describe the recovery of trauma intensive care patients up to six months post hospital discharge.

\section{METHODS}

A prospective cohort study of adult patients was undertaken in one tertiary referral hospital in South-East Queensland Australia. Recruitment extended from June 2008 to August 2010. This paper reports on participants' recovery at one and six months after hospital discharge.

\section{Participants}

Consecutive adults ( $\geq 18$ years) were invited to participate in this study if they met the inclusion criteria of (i) allocated an injury code including International Classification of Diseases, $10^{\text {th }}$ Revision - Australian Modification (ICD-10-AM) code: S00 - S99, T00 - T35, T63, T66 - 72 or T $75-77$ and (ii) admitted to the ICU for the acute treatment of that injury. Patients were excluded for the following reasons: (i) spinal cord injuries with sensory and/or motor loss; (ii) burn injuries to $>20 \%$ body surface area; (iii) traumatic brain injuries with a Glasgow Coma Score $<14$ after 24 hours or on extubation; (iv) history of psychosis or self-inflicted injury; (v) inability to communicate in English; (vi) prisoners; (vii) people without a home telephone; (viii) palliative care / patients expected to die. Exclusion criteria (i) to (iii) were designed to exclude patients who usually experience a significantly different recovery phase due to differing acute, rehabilitation and post-discharge care, when compared to the majority of seriously injured people. The remaining exclusion criteria related to the practicalities of following up patients. 


\section{Data Collection}

Potential participants were identified during their admission to the ICU, and were approached regarding the study several days after transfer to a hospital ward.

Following informed consent, and at a time when discharge from hospital was planned during the next 72 hours, the initial questionnaire was completed. This questionnaire included demographic details and the Physical Function sub-scale of the Medical Outcome Study Short Form-36 Version 2 (SF-36) based on function in the week prior to the injury (Ware \& Sherbourne 1992). Next of kin assisted with completion of this questionnaire when required.

Follow-up questionnaires were posted to the participants at one and six months post hospital discharge, with a covering letter providing instructions for participants to complete the questionnaires within the next week at a time convenient to them, but without assistance from family members/ friends. An appointment for a phone interview was then scheduled so participants could read their answers to the research assistant. A postage paid envelope was also provided if the participant preferred to return their questionnaire by mail. For a small number of participants email communication was used. Up to five attempts to contact participants were made at each of the follow-up points. This combination of mail and telephone contact was designed to provide participants with time to consider their answers to each question while optimizing follow-up rates by not relying exclusively on questionnaires being returned via the mail. Other procedures to optimise retention of participants included obtaining contact details for two family members/friends and their General Practitioner at the time of enrolment so that the study team had alternative methods of contacting them if they relocated, providing a free call telephone number for 
participants to contact the study team and sending regular postcards to participants reminding them of the study.

Data were collected from multiple sources including the participants, their health care records and the Queensland Trauma Registry (QTR). Data quality within the QTR was optimised by a combination of using trained coders, direct extraction from the health care record, a series of education and audit processes and the conduct of logic and range checks on collected data. The outcome variable of health status was measured via the SF-36. Variables collected included: demographic details (age, sex, marital status, indigenous status, highest educational level); socioeconomic details (work status, household income, private health insurance); pre-injury health (physical function as measured by the SF-36 physical function subscale, co-morbidities); injury characteristics (mechanism of injury, body region with most severe injury, injury severity score [ISS]); acute care factors (severity of illness [Acute Physiology and Chronic Health Evaluation - APACHE], ICU length of stay [LOS], hospital LOS, underwent surgery, developed a complication); and post-acute factors (self-efficacy, illness perception, perceived social support and psychological status as measured by the Kessler Psychological Distress Scale [K10] and the Post-Traumatic Stress Disorder [PTSD] Civilian Checklist).

Illness Perception: The Brief Illness Perception Questionnaire (BIPQ) contained eight items using a $0-10$ response scale to assess cognitive illness and emotional response (Broadbent et al. 2006), and another item examining causal factors in the participants' illness. The word 'illness' was replaced with 'injury' in this study. Scoring involved the reversing of items 3,4 and 7 , then the summing of the eight items for a total score. 
A higher score reflected a perception that the injury exerted more influence on the participant's life. Good predictive validity has been demonstrated in a cohort of myocardial infarction patients while discriminant validity was confirmed by identifying differences in IPQ scores in patients with a range of acute and chronic diseases including myocardial infarction, asthma, diabetes and colds (Broadbent et al. 2006). Reliability of the Brief IPQ in the present study was good (internal consistency coefficient at one month $\alpha=0.74$; six months $\alpha=0.84$ ).

Social support: The Multidimensional Scale of Perceived Social Support (MSPSS) used a 12-item Likert-type response (1: very strongly disagree to 7: very strongly agree) to assess an individual's perception of how much he or she received social support, with higher scores indicating greater perceived social support (Zimet et al. 1988). Four items assessed each of the three sources of social support (family, friends and significant others); subscale and total scores were obtained by summing scores and dividing by the relevant number of items. The validity of these subscales has been demonstrated by the scale developers (Zimet et al. 1990). Reliability of the MSPSS at one and six months was between $\alpha$ 0.95- 0.97 for the total scale and $\alpha 0.89-0.95$ for each of the subscales.

Self-Efficacy: The Self-Efficacy Scale (SES) is a six item, 10-point Likert scale designed to measure patients' confidence in undertaking daily activities, in other words their perceived ability to undertake tasks and achieve results. Total SES was derived by taking the average of the six items with responses ranging from one (not at all confident) to 10 (totally confident); the structure and scoring of this scale has shown good validity in patients with chronic health problems (Lorig 1996, Lorig et al. 
2001). Reliability of the one and six month SES in the present study was good (internal consistency coefficient $\alpha=0.93$ and $\alpha=0.94$ respectively).

Psychological Distress: The Kessler Psychological distress scale (K10) measured 10 items related to psychological distress on a five point scale (1: none of the time to 5: all of the time), higher scores indicated greater distress (Kessler et al. 2002). This scale has previously demonstrated high levels of validity in large cohorts in both Australia and the United States of American (Kessler et al. 2002) and reliability at one and six months in the current study was excellent (internal consistency coefficient $\alpha=0.89$ and $\alpha=0.93$ respectively). K10 cut-off scores developed by the Clinical Research Unit for Anxiety and Depression (CRUfAD), University of New South Wales provided further interpretation of prevalence levels of psychological distress (Australian Bureau of Statistics 2001).

Post-Traumatic Stress: The PTSD Checklist - Civilian Version (PCL-C) measured trauma related stress on a self-report Likert scale (1: not at all, 5: extremely) of 17 items (Weathers et al. 1993), with higher scores indicating more post-traumatic stress. A multifaceted algorithm was also applied to derive PTSD symptoms consistent with a diagnosis of PTSD (i.e. individual meets Diagnostic and Statistical Manual of Mental Disorders IV symptom criteria). Combining methods as previously validated provided insight into both severity and patterns of symptoms (Weathers et al. 1993). Evidence cited by the National Centre for PTSD suggested a 10-20 unit change as clinically meaningful (http://www.ptsd.va.gov/professional/pages/assessments/ptsdchecklist.asp). Reliability of the one and six month PCL-C total score in the present study was excellent (internal consistency coefficient $\alpha=0.93$ for both). 
Health Status: was measured via the SF-36v2; a 36 item instrument that measured health status across eight domains or sub-scales (Physical Functioning [PF], Role Functioning, Bodily Pain, General Health, Vitality, Social Functioning, Role Emotion and Mental Health) and two component summary scores that provided an overall estimate of physical and mental health (Physical Component Score, PCS, and Mental Component Score, MCS). Physical health at the time of injury was assessed through retrospective completion of the PF subscale. The SF-36 is well validated in many different populations in both the acute and chronic setting (Ware \& Sherbourne 1992).

The eight sub-scales and two component scores were computed and presented as norm-based T-scores allowing for easier interpretation (standardised scores with a population mean of 50 and a standard deviation of 10). Higher scores on each of the sub-scale and summary scores indicated better health status. Participants were requested to complete the questionnaires based on their experience over the past four weeks.

QualityMetric Health Outcomes ${ }^{\mathrm{TM}}$ Scoring Software 4.5 was used to produce raw scores (range $0-100$ ), however as the software scoring algorithm was determined from United States population norms, T-scores were calculated using Australian normed mean T-scores (Hawthorne et al. 2007). The PCS and MCS were based on the same Australian norms and were weighted with Australian coefficients.

\section{Data analysis}

Recruitment numbers, eligible patient numbers, numbers consenting, the participant numbers at each measurement wave, and attrition data are reported using a 
CONSORT style approach. Statistical analyses were performed using Stata 11 (Statacorp/Texas). Data were cleaned and checked for missing values and invalid responses. Continuous/interval data were expressed as mean \pm standard deviation (SD) or median \pm interquartile range (IQR) based on normality of data. Categorical data were presented as counts and percentages.

Distribution checks were performed on all continuous/interval data involving comparisons over time and appropriate parametric or non-parametric tests were performed. All statistical tests were two tailed and considered significant at $\alpha<0.05$. A repeated measures t-test was used to compare continuous normally distributed data at one and six months, with the Wilcoxon signed-rank test used when data distributions departed from normal. McNemar's test was used to compare changes in proportions over time for dichotomous categorical data and Bowker's test of symmetry to assess any shifts over time for categorical data with more than two categories. Comparison of the baseline data for those who did and did not respond to the one and six month surveys has been undertaken to examine representativeness of the final sample.

Scores were calculated if a respondent had not answered all items with scores computed when one item was missing. If two or more items on a measure were missing, summary scores were not computed. An estimate was substituted for a missing data item based on the individual response to other items, in this case the average score of the completed items in the same scale and/or subscale, was used. Calculations for SF-36 health domains employed a missing score estimator method incorporated within the QualityMetric Scoring Software. 


\section{Ethical Considerations}

Approval to conduct this study was gained from the Human Research Ethics Committee's (HREC) of the participating hospital and university. All participants provided informed consent prior to data collection and were free to withdraw from the study at any time. At the beginning of the phone call to gain the results of each questionnaire the participant's willingness to continue in the study was ascertained. The routine operation of the QTR is approved by the HRECs of all participating hospitals and The University of Queensland, and is recognized within the provisions of the Health Legislation Amendment Regulation (no. 7) 2006 under the Health Services Act 1991 (Queensland) for the purpose of collection data.

\section{RESULTS}

One hundred and twenty three participants consented to enrolment and completed the baseline questionnaire during their hospitalisation for the acute treatment of injury. Participant numbers reduced to 93 and 88 at one and six months respectively (Figure 2). Participants were just under 40 years old and were predominantly male. Approximately half of the cohort was married or in a defacto relationship, and a similar proportion were in full time work. Other demographic details are outlined in Table 1. Forty percent of the cohort smoked and one quarter had private health insurance although a further quarter of the cohort was covered by other insurance such as workers compensation in relation to their current injury (Table 1).

Responders were similar to non-responders at both one and six months except in regard to age. Responders were significantly older than non-responders at one month (43 vs 31 years, $\mathrm{z}=-2.24, p=0.025$ ) and six months (43 vs 33, $\mathrm{z}=-2.26, p=0.024)$, 
demonstrating a larger loss of younger participants at follow-up. Responders and nonresponders at one month did not differ in their reported pre-injury PF scores which were 53.7 and 52.9 respectively $\left(\mathrm{t}_{121}=-0.40, p=0.691\right)$.

Median hospital length of stay was 20 days, with just under 3 days spent in ICU (Table 3). The median ISS for patients was 19 (IQR 13-29) with the largest number of injures involving the head, face and neck (33\%), follow by the thorax (26\%) and lower extremities $(22 \%)$. Two thirds of injuries were a result of a road traffic crash and $15 \%$ due to a fall. Just under a third of patients underwent surgery during the acute treatment period of their hospital stay, while just over a third of patients developed a complication while in hospital (Table 3).

During 72 hours prior to hospital discharge a family conference was documented in one out of five patients, with the majority being completed in person $(90 \%)$. Just over half of the family conferences were held by an allied health worker, typically an occupational therapist.

Within the first month post hospital discharge, the majority of patients had visited at least one healthcare provider (HCP), with patients seeing on average three different HCP (IQR:1-4) since leaving hospital (Table 4). Patients most frequently visited a general practitioner, pharmacist, physiotherapist or occupational therapist. Sixty three percent of patients visited a HCP via the public sector, and $16 \%$ reported seeing a HCP in private sector. Around 14\% of patients' had the HCP visit them in their home. 
The majority of patients followed up at six months had visited at least one HCP in the preceding five months, seeing on average three different HCP in that period (IQR: 24.5). The most commonly accessed HCP were GPs, pharmacists, physiotherapists, orthopedic surgeons or hospital based doctors (Table 4). Again, the majority of HCP were accessed via the public sector (34\%), 26\% visiting a HP in private sector and $2 \%$ seeing a community sector HCP. Just over $3 \%$ of patient reported a HCP had visited them at home.

One month post discharge half of all patients had organised some form of support service, with the majority $(80 \%)$ using no more than two services since returning home (Table 4). These services predominantly consisted of supported accommodation, either formal or from relatives/friends, nursing services, home modifications and travel assistance and continued to be required six months after discharge from hospital.

Participant's perception of their social support decreased slightly over time (Table 5). Change in the family component of support showed the most significant decrease over time $\left(\mathrm{t}_{78}=2.75, p=0.007\right)$, followed by significant others $\left(\mathrm{t}_{76}=2.02, p=0.0 .047\right)$, with no change in perceived friends' support $\left(\mathrm{t}_{78}=1.08, p=0.285\right)$ (Table 5).

There was no significant difference in average PTSD symptom scores, or proportion of the cohort classified as symptomatic for PTSD, at one and six months post discharge (Table 5). There were eight patients who were non-symptomatic at one month but symptomatic at six months and a further six patients who were symptomatic at one month but non-symptomatic at six months. The distribution 
between the symptomatic and non-symptomatic groups at one and six months was not statistically significant (Exact McNemar $p=0.791)$.

Psychological distress K10 scores did not show any significant change over time $\left(\mathrm{t}_{78}=\right.$ $1.0, p=0.316$ ) (Table 5). Amongst participants who completed data collection at one and six months, around $70 \%(\mathrm{n}=55)$ did not change CRUfAD categories over this time period. Four participants (5\%) classified as 'low or medium-risk' at one month were classified as 'high-risk' at six months. Conversely 11 participants (14\%) classified as 'high risk' at one month were classified as 'low or medium risk' at six months. Overall shifts between CRUfAD categories from one to six months were not statistically significant (Bowker's test of symmetry $=1.0, \mathrm{df}=3, p=0.801$ ).

Self-efficacy increased by a small amount from one to six months, but this change was not statistically non-significant $\left(\mathrm{t}_{78}=-0.92, p=0.360\right)$ (Table 5$)$. Illness perception scores reduced by an average of 4 units from one to six months and this reduction was statistically different $\left(\mathrm{t}_{78}=3.15, p=0.002\right)$ (Table 5).

The average PF score was reported as slightly above the Australian norms pre-injury (Figure 3). All sub-scale scores were significantly below the norms by one month post discharge ( $p<0.001$ for all sub-scales). Most subscale scores increased significantly from one to six months post discharge (Table 6) but still remained significantly below the norms in all areas ( $<<0.001$ for all subscales) (Figure 3$)$. Both component summary scores also remained significantly below the norms $(p<0.001$ for both summary scores). 


\section{DISCUSSION}

The participants enrolled in this cohort were similar to the global Queensland trauma population in regard to age, although males were slightly over-represented (Dallow et al. 2011). Injuries that occurred as a result of road traffic crashes were also over represented, perhaps reflecting the more severely injured patients who required admission to ICU.

Only half of the participants were in full-time work at the time of their injury, with a further one fifth in part time or casual work resulting in almost three quarters of the group being in paid employment. Six months post injury only a total of $50 \%$ of the participants were in any work regardless of whether it was full-time, part-time or casual. The finding of approximately $70 \%$ of participants working prior to the injury is lower than that reported by O'Donnell and colleagues in a similar Australian cohort (O'Donnell et al. 2010), but consistent with that reported by Harris and colleagues in a larger Australian study where they also found a reduction in employment after hospital admission for the treatment of injury from approximately $70 \%$ to $50 \%$ (Harris et al. 2008). The reduction in employment does not appear to be due to systematic loss to follow-up of those in paid employment, but movement from paid employment to disability and unemployment benefits. For example, when considering the 88 respondents at six months, 46 had been in full time employment at the time of their injury, this had reduced to 29 in full time employment at six months with 12 moving to disability, unemployment and other benefits.

Only one quarter of the participants had private health insurance, although a further $30 \%$ had other insurance relevant to this injury such as workers compensation. 
Almost half of the participants had no insurance cover for treatment of their injuries and so are likely to remain dependent on the public health system for their rehabilitation.

Study participants had an average ISS of 19 and spent an average of three days in ICU, but their average hospital stay was almost three weeks. The pattern of approximately $15 \%$ of the hospital stay being in ICU was slightly below other Australian cohorts where just over $20 \%$ of hospital time was in ICU (Harris et al. 2008, O'Donnell et al. 2010), and significantly below patterns reported in the USA and Europe where $35-60 \%$ of the hospitalisation was spent in ICU (Holtslag et al. 2007, Livingston et al. 2009, Ringdal et al. 2009, Toien et al. 2010). This low proportion of hospitalisation in ICU may reflect organisational patterns in Australia where ICU beds represent a smaller proportion of the hospital, and therefore patients are transferred to ward care while they remain more severely ill than in some other countries.

The ongoing reliance on healthcare and social service providers has not been previously reported in this population. Overall healthcare provider utilisation increased from one month to six months, however part of this increase may have been due to the longer timeframe. More than $20 \%$ of participants accessed the services of a psychologist, while close to half the participants used physiotherapy services and one third used occupational therapy services. Half of the participants required social services in the first month, predominantly supported accommodation, nursing services or home modifications, however this had reduced to $36 \%$ by six months post injury. 
This ongoing use of healthcare and social services represents a significant commitment in terms of time and money for injured patients.

More than $20 \%$ of patients reported symptoms of PTSD and more than half of the participants reported psychological distress. Although the current study only examined symptoms, rather than a diagnosis, of PTSD the incidence is roughly equivalent to other reports in this population (Cuthbertson et al. 2004, Jackson et al. 2007b, O'Donnell et al. 2010). We have not collected the data to identify the causes of psychological compromise in this group of patients, but the two most likely causes are the original event that caused the injury or the experience while admitted to ICU, or a combination of these (DiMartini et al. 2007, O'Donnell et al. 2010).

Despite the overall incidence of psychological status not changing between the two follow-up time points, there were a number of patients who moved from symptomatic to non-symptomatic and a similar number who moved in the opposite direction. This suggests that, while some patients' psychological status improves over the first six months post hospitalisation, there are other patients who experience deterioration in their psychological status through this time frame. This is consistent with the known pathology of PTSD (Friedman et al. 2007). This finding indicates the need for ongoing surveillance of psychological status and availability of treatment. It also emphasises the need for measurement of the effect of any intervention on psychological status after injury or ICU admission to extend beyond at least six months. 
Self-efficacy reported by the participants in this study was above average; no other reports of self-efficacy in the severely injured population could be identified but the levels reported here were higher than that reported by injured ward based patients in Hong Kong (Wong et al. 2010). Why patients who have been severely injured and spent time in intensive care might have high self-efficacy is uncertain. It could be that patients feel more confident one and six months after injury than they were immediately after their injury. In this study we did not measure self-efficacy while patients were still in hospital and so cannot confirm this suggestion. Self-efficacy levels did increase at six months compared to one month, although not to a significant level.

Illness perception decreased significantly between one and six months, indicating that participants' perception of the influence the injury had on their lives was reducing. It is difficult to make comment regarding the importance of this finding given the absence of other reports of illness perception in either the seriously injured or intensive care population, but illness perceptions reported here were lower than in moderately injured patients in both Australia and internationally (Aitken et al. 2012, Lee et al. 2010).

The role of both self-efficacy and illness perception on outcome in the critically injured population has not been explored. There is evidence that self-efficacy is related to outcome in the chronic health population (Lorig et al. 2001, Shnek et al. 1997). Similarly, illness perception is related to health outcomes in those with chronic illness (Covic et al. 2004, Rutter \& Rutter 2007), as well as in the moderately injured population (Aitken et al. 2012, Lee et al. 2010). The final results of the current study 
will contribute to an understanding of the potential role of both self-efficacy and illness representation in the critically injured group.

Consistent with other reports of the injured and critically ill population, participants reported health related quality of life to be below national norms in all sub-scales one month post hospital discharge. Although remaining significantly below norms, most physical aspects of quality of life had significantly improved from one to six months with the exception being general health. Less improvement was identified in the mental aspects of quality of life, with only vitality and social function improving significantly, but still remaining below national norms. These findings suggest that psychological aspects of health are still improving at six months post injury or intensive care admission. Studies conducted in this arena should measure patient status beyond this time point.

\section{CONCLUSION}

Trauma patients who require admission to intensive care remain in hospital for approximately three weeks. In the Australian setting a majority of this time is spent in acute care wards. After discharge from hospital this cohort of trauma patients reported significant reliance on ongoing healthcare professional utilisation and social services, and ongoing compromised health related quality of life and psychological health that persists at six months.

\section{RELEVANCE TO CLINICAL PRACTICE}

This study highlights the ongoing reliance on health care and social support services post hospital discharge. To ensure these care requirements are met effective discharge 
planning and communication across the care continuum with health care providers in the community environment is essential. Compromised psychological health is confirmed for a significant number of patients. The lengthy time that patients spend in acute care wards may provide an opportunity for interventions directed at minimising this compromise. 


\section{ACKNOWLEDGEMENTS}

This study was supported by the PA Research Foundation.

We thank Jennie Abbey who undertook much of the participant recruitment and data collection, as well as Regina Boyce, Anne-Marie Kelly and Kelly Bures who screened and recruited patients and Liz Burmeister who assisted with data collection and study coordination.

\section{CONTRIBUTIONS}

Study design - LMA, WC, MS, CJ

Data collection and analysis - LMA, BM

Manuscript preparation - LMA, WC, MS, CJ, BM 


\section{REFERENCES}

Aitken LM, Chaboyer W, Kendall E \& Burmeister E (2012): Health status after traumatic injury. J Trauma Acute Care Surg 72, 1702-1708.

Aitken LM, Davey TM, Ambrose J, Connelly LB, Swanson C \& Bellamy N (2007): Health outcomes of adults 3 months after injury. Injury 38, 19-26.

Australian Bureau of Statistics (2001) Use of the Kessler Psychological Distress Scale in ABS Health Surveys: Information Paper, cat no. 4817.0.55.001. ABS, Canberra.

Australian Institute of Health and Welfare (AIHW) (2010) Australia's Health 2010. In Australia's health series no. 12. Cat. no. AUS 122. AIHW, Canberra.

Badia X, Diaz-Prieto A, Gorriz MT, Herdman M, Torrado H, Farrero E \& Cavanilles JM (2001): Using the EuroQol-5D to measure changes in quality of life 12 months after discharge from an intensive care unit. Intensive Care Medicine 27, 1901-1907.

Broadbent E, Petrie KJ, Main J \& Weinman J (2006): The brief illness perception questionnaire. Journal of Psychosomatic Research 60, 631-637.

Connelly J, Chell S, Tennant A, Rigby AS \& Airey CM (2006): Modelling 5-year functional outcome in a major traumatic injury survivor cohort. Disability and Rehabilitation 28, 629-636.

Covic A, Seica A, Gusbeth-Tatomir P, Gavrilovici O \& Goldsmith DJ (2004): Illness representations and quality of life scores in haemodialysis patients. Nephrology, Dialysis, Transplantation 19, 2078-2083.

Cuthbertson BH, Hull A, Strachan M \& Scott J (2004): Post-traumatic stress disorder after critical illness requiring general intensive care. Intensive Care Medicine 30, 450-455.

Dallow N, Lang J, Harvey K, Pollard C, Tetsworth K \& Bellamy N (2011) Description of serious injury throughout Queensland 2009. Centre of National Research on Disability and Rehabilitation Medicine, Herston.

DiMartini A, Dew MA, Kormos R, McCurry K \& Fontes P (2007): Posttraumatic stress disorder caused by hallucinations and delusions experienced in delirium. Psychosomatics 48, 436-439.

Friedman MJ, Keane TM \& Resick PA (2007) Handbook of PTSD, Science and Practice The Guildford Press New York

Harris IA, Young JM, Rae H, Jalaludin BB \& Solomon MJ (2008): Predictors of general health after major trauma. Journal of Trauma 64, 969-974.

Hawthorne G, Osborne RH, Taylor A \& Sansoni J (2007): The SF36 Version 2: critical analyses of population weights, scoring algorithms and population norms. Quality of Life Research 16, 661-673.

Holtslag HR, van Beeck EF, Lindeman E \& Leenen LPH (2007): Determinants of Long-Term Functional Consequences After Major Trauma. Journal of Trauma 62, 919-927.

Hyder AA \& Aggarwal A (2009): The increasing burden of injuries in Eastern Europe and Eurasia: making the case for safety investments. Health Policy 89, 1-13.

Jackson JC, Hart RP, Gordon SM, Hopkins RO, Girard TD \& Wesley E (2007a): Post-traumatic stress disorder and post-traumatic stress symptoms following critical illness in medical intensive care unit patients: assessing the magnitude of the problem. Critical Care 11, 1-11.

Jackson JC, Obremskey W, Bauer R, Greevy R, Cotton B, Anderson V, Song Y \& Ely EW (2007b): Long-Term Cognitive, Emotional, and Functional Outcomes 
in Trauma Intensive Care Unit Survivors Without Intracranial Hemorrhage. The Journal of Trama 62, 80-88.

Kessler RC, Andrews G, Colpe LJ, Hiripi E, Mroczek DK, Normand SL, Walters EE \& Zaslavsky AM (2002): Short screening scales to monitor population prevalences and trends in non-specific psychological distress. Psychological Medicine 32, 959-976.

Korosec Jagodic H, Jagodic K \& Podbregar M (2006): Long-term outcome and quality of life of patients treated in surgical intensive care: a comparison between sepsis and trauma. Critical Care 10, R134.

Lee BO, Chaboyer W \& Wallis M (2010): Illness representations in patients with traumatic injury: a longitudinal study. Journal of Clinical Nursing 19, 556563.

Livingston DH, Tripp T, Biggs C \& Lavery RF (2009): A fate worse than death? Long-term outcome of trauma patients admitted to the surgical intensive care unit. Journal of Trauma 67, 341-348; discussion 348-349.

Lorig K (1996) Outcome measures for health education and other health care interventions Sage Publications Inc., Thousand Oaks:.

Lorig KR, Sobel DS, Ritter PL, Laurent D \& Hobbs M (2001): Effect of a selfmanagement program on patients with chronic disease. Effective Clinical Practice 4, 256-262.

Mata GV, Fernandez RR, Aragon AP, Carmona AG, Mondejar EF \& Navarro PN (1996): Analysis of quality of life in polytramatized patients two years after discharge from an intensive care unit. Journal of Trauma, Injury, Infection and Critical Care 41, 326-332.

Mathers C, Vos T \& C. S (1999) The Burden Of Disease And Injury In Australia. AIHW Cat. No. PHE 17. Australian Institute of Health and Welfare, Canberra.

Needham DM, Davidson J, Cohen H, Hopkins RO, Weinert C, Wunsch H, Zawistowski C, Bemis-Dougherty A, Berney SC, Bienvenu OJ, Brady SL, Brodsky MB, Denehy L, Elliott D, Flatley C, Harabin AL, Jones C, Louis D, Meltzer W, Muldoon SR, Palmer JB, Perme C, Robinson M, Schmidt DM, Scruth E, Spill GR, Storey CP, Render M, Votto J \& Harvey MA (2012): Improving long-term outcomes after discharge from intensive care unit: report from a stakeholders' conference. Critical Care Medicine 40, 502-509.

Niskanen M, Ruokonen E, Takala J, Rissanen P \& Kari A (1999): Quality of life after prolonged intensive care. Critical Care Medicine 27, 1132-1139.

O'Donnell ML, Creamer M, Holmes AC, Ellen S, McFarlane AC, Judson R, Silove D \& Bryant RA (2010): Posttraumatic Stress Disorder After Injury: Does Admission to Intensive Care Unit Increase Risk? Journal of Trauma 28, 28.

Peden M, McGee K \& Krug E (2002) Injury: A Leading Cause Of The Global Burden Of Disease, 2000. World Health Organisation, Geneva.

Richmond TS \& Aitken LM (2011): A model to advance nursing science in trauma practice and injury outcomes research. Journal of Advanced Nursing 67, 2741 $-2753$.

Richmond TS, Kauder D, Hinkle J \& Shults J (2003): Early predictors of long-term disability after injury. American Journal of Critical Care. 12, 197-205.

Ringdal M, Plos K, Lundberg D, Johansson L \& Bergbom I (2009): Outcome after injury: memories, health-related quality of life, anxiety, and symptoms of depression after intensive care. Journal of Trauma 66, 1226-1233. 
Rutter CL \& Rutter DR (2007): Longitudinal analysis of the illness representation model in patients with irritable bowel syndrome (IBS). J Health Psychol 12, 141-148.

Shnek ZM, Foley FW, LaRocca NG, Gordon WA, DeLuca J, Schwartzman HG, Halper J, Lennox S \& Irvine J (1997): Helplessness, self-efficacy, cognitive distortions, and depression in multiple sclerosis and spinal cord injury. Annals of Behavioral Medicine 19, 287-294.

Sluys K, Haggmark T \& Iselius L (2005): Outcome and quality of life 5 years after major trauma. Journal of Trauma 59, 223-232.

Toien K, Myhren H, Bredal IS, Skogstad L, Sandvik L \& Ekeberg O (2010): Psychological distress after severe trauma: a prospective 1-year follow-up study of a trauma intensive care unit population. Journal of Trauma 69, 15521559.

Ware JE \& Sherbourne CD (1992): The MOS 36-item short-form health survey (SF36): Conceptual framework and item selection. Medical Care 30, 473-483.

Weathers FW, Litz BT, Herman DS, Huska JA \& Keane TM (1993) The PTSD Checklist (PCL): reliability, validity and diagnostic utility. In Annual Meeting of International Society for Traumatic Stress Studies, San Antonio, TX.

Wong EM, Chan SW \& Chair SY (2010): Effectiveness of an educational intervention on levels of pain, anxiety and self-efficacy for patients with musculoskeletal trauma. Journal of Advanced Nursing 66, 1120-1131.

Zimet GD, Dahlen NW, Zimet SG \& Farley GK (1988): The Mulitdimensional Scale of Perceived Social Support. Journal of Personality Assessment 52, 30 - 41

Zimet GD, Powell SS, Farley GK, Werkman S \& Berkoff KA (1990): Psychometric characteristics of the Multidimensional Scale of Perceived Social Support. Journal of Personality Assessment 55, 610-617. 
Table 1. Demographic characteristics: Baseline, 1 month and 6 months

\begin{tabular}{|c|c|c|c|}
\hline & $\begin{array}{c}\text { Baseline } \\
\mathrm{n}=123\end{array}$ & $\begin{array}{c}1 \text { month } \\
\mathbf{n}=93\end{array}$ & $\begin{array}{c}6 \text { months } \\
n=88\end{array}$ \\
\hline \multirow[t]{2}{*}{ Age (years) ${ }^{a}$} & \multicolumn{3}{|c|}{ Median (IQR) } \\
\hline & $37(28-55)$ & $\mathrm{n} / \mathrm{a}$ & $\mathrm{n} / \mathrm{a}$ \\
\hline Gender & \multicolumn{3}{|c|}{ Frequency (\%) } \\
\hline Male & $102(82.9)$ & \multirow[t]{2}{*}{$\mathrm{n} / \mathrm{a}$} & \multirow[t]{2}{*}{$\mathrm{n} / \mathrm{a}$} \\
\hline Female & $21(17.1)$ & & \\
\hline \multicolumn{4}{|c|}{ Aboriginal \&Torres Strait Islander Status } \\
\hline Yes & $4(3.3)$ & \multirow[t]{2}{*}{$\mathrm{n} / \mathrm{a}$} & \multirow[t]{2}{*}{$\mathrm{n} / \mathrm{a}$} \\
\hline No & $119(96.7)$ & & \\
\hline \multicolumn{4}{|l|}{ Marital Status } \\
\hline Married/De facto & $57(46.7)$ & $47(50.5)$ & $43(48.9)$ \\
\hline Never married & $40(32.8)$ & $30(32.3)$ & $28(31.8)$ \\
\hline Separated/ Divorced & $21(17.2)$ & $14(15.0)$ & $15(17.0)$ \\
\hline Widowed & $4(3.3)$ & $2(2.2)$ & $2(2.3)$ \\
\hline \multicolumn{4}{|c|}{ (1 missing) } \\
\hline \multicolumn{4}{|l|}{ Employment } \\
\hline Full time work & $64(52.0)$ & $39(42.4)$ & $30(34.0)$ \\
\hline Part time & $7(5.7)$ & $3(3.3)$ & $7(8.0)$ \\
\hline Casual work & $18(14.6)$ & $4(4.3)$ & $7(8.0)$ \\
\hline Retired & $12(9.8)$ & $10(10.9)$ & $12(13.6)$ \\
\hline Student & $4(3.3)$ & $3(3.3)$ & $3(3.4)$ \\
\hline Disability benefit & $7(5.7)$ & $13(14.1)$ & $7(8.0)$ \\
\hline Unemployed & $9(7.3)$ & $12(13.0)$ & $15(17.0)$ \\
\hline \multirow[t]{2}{*}{ Other } & $2(1.6)$ & $8(8.7)$ & $7(8.0)$ \\
\hline & \multicolumn{3}{|c|}{ (1 missing) } \\
\hline \multirow[t]{2}{*}{ Hours of work per week } & \multicolumn{3}{|c|}{ Median (IQR) } \\
\hline & $40(37-50)_{(\mathrm{n}=86)}$ & $40(37-50)_{(\mathrm{n}=31)}$ & $38(33-45)_{(\mathrm{n}=40)}$ \\
\hline Highest Educational Level & & \multicolumn{2}{|l|}{ Frequency (\%) } \\
\hline Primary School & $3(2.4)$ & $\mathrm{n} / \mathrm{a}$ & $\mathrm{n} / \mathrm{a}$ \\
\hline Secondary $(8,9,10)$ & $40(32.5)$ & & \\
\hline Secondary $(11,12)$ & $23(18.7)$ & & \\
\hline Trade/vocational training & $42(34.2)$ & & \\
\hline University education & $15(12.2)$ & & \\
\hline \multicolumn{4}{|l|}{ Household Income (\$AUD) } \\
\hline \multirow[t]{2}{*}{$\$ 0-29999$} & $43(35.3)$ & $39(42.9)$ & $40(46.0)$ \\
\hline & $42(34.4)$ & $24(26.4)$ & $26(29.9)$ \\
\hline
\end{tabular}




\begin{tabular}{|c|c|c|c|}
\hline$\$ 30000-59999$ & $25(20.5)$ & $16(17.6)$ & $10(11.5)$ \\
\hline$\$ 60000-89999$ & $12(9.8)$ & $12(13.2)$ & $11(12.6)$ \\
\hline$\$ 90000$ or more & (1 missing) & (2 missing) & (1 missing) \\
\hline \multicolumn{4}{|l|}{ Smoking Status } \\
\hline Yes & $50(40.6)$ & $\mathrm{n} / \mathrm{a}$ & $\mathrm{n} / \mathrm{a}$ \\
\hline No & $73(59.4)$ & & \\
\hline \multicolumn{4}{|c|}{ Private Health Insurance } \\
\hline Yes & $32(26.0)$ & $24(25.8)$ & $24(27.3)$ \\
\hline No & $91(74.0)$ & $69(74.2)$ & $64(72.7)$ \\
\hline \multicolumn{4}{|c|}{ Type of Health Insurance ${ }^{b}$} \\
\hline Hospital only & $5(15.6)$ & $2(8.3)$ & $2(8.7)$ \\
\hline Extra only & $1(3.1)$ & $3(12.5)$ & $1(4.4)$ \\
\hline \multirow[t]{2}{*}{ Both } & $26(81.3)$ & $19(79.2)$ & $20(86.9)$ \\
\hline & & & (1 missing) \\
\hline \multicolumn{4}{|l|}{ Other Insurance } \\
\hline Yes & $38(30.9)$ & $28(30.1)$ & $28(31.8)$ \\
\hline No & $85(69.1)$ & $65(69.9)$ & $60(68.2)$ \\
\hline
\end{tabular}

${ }^{\mathrm{N} / \mathrm{A}}$ Not assessed at time point, ${ }^{\mathrm{a}}$ Age at enrolment; ${ }^{\mathrm{b}}$ Only includes participants who indicated 'yes' to private health insurance 
Table 2. Comparison between Responders and Non responders at 1 month and 6 months

\begin{tabular}{|c|c|c|c|c|}
\hline & \multicolumn{2}{|c|}{1 month } & \multicolumn{2}{|c|}{6 months } \\
\hline & $\begin{array}{c}\text { Responders } \\
\mathbf{n}=93\end{array}$ & 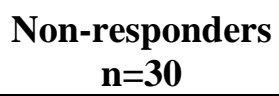 & $\begin{array}{c}\text { Responders } \\
\mathbf{n}=\mathbf{8 8}\end{array}$ & $\begin{array}{c}\begin{array}{c}\text { Non-responders } \\
\mathrm{n}=35\end{array}\end{array}$ \\
\hline \multirow[t]{2}{*}{ Age (years) ${ }^{a}$} & \multicolumn{4}{|c|}{ Median (IQR) } \\
\hline & $43(28-58)$ & $31(27-42)$ & $43(28-59)$ & $33(26-44)$ \\
\hline Gender $^{\mathrm{a}}$ & \multicolumn{4}{|c|}{ Frequency (\%) } \\
\hline Male & $77(82.8)$ & $25(83.3)$ & $71(80.7)$ & $31(88.6)$ \\
\hline Female & $16(17.2)$ & $5(16.7)$ & $17(19.3)$ & $4(11.4)$ \\
\hline \multicolumn{4}{|c|}{$\begin{array}{ll}\text { Injury and acute care characteristics }{ }^{a} & \text { Median (IQR) }\end{array}$} & \\
\hline ISS $^{b}$ & $19(13-29)$ & $19(13-29)$ & $17(12-29)$ & $24(14-29)$ \\
\hline APACHE III & $41(30-53)$ & $36(27-48)$ & $42(30-53)$ & $37(27-52)$ \\
\hline Hospital LOS & $20.2(9.8-39.2)$ & $20.0(8.9-38.9)$ & $18.2(9.7-39.5)$ & $20.8(9.7-38.8)$ \\
\hline ICU LOS & $2.7(1.1-7.3)$ & $3.3(1.5-9.6)$ & $2.8(1.1-7.9)$ & $3.1(1.5-6.7)$ \\
\hline
\end{tabular}


Table 3. Injury and Acute Care Characteristics

\begin{tabular}{|c|c|}
\hline Body region of main injury ${ }^{a}$ & Frequency (\%) \\
\hline Head, Face \& Neck & $40(33.1)$ \\
\hline Thorax & $31(25.6)$ \\
\hline Abdomen & $16(13.2)$ \\
\hline Spine & $4(3.3)$ \\
\hline Upper Extremity & $3(2.5)$ \\
\hline Lower Extremity & $27(22.3)$ \\
\hline \multicolumn{2}{|l|}{ Mechanism of Injury $^{\text {a }}$} \\
\hline Road Traffic Crash & $80(66.1)$ \\
\hline Fall & $18(14.9)$ \\
\hline Collision & $5(4.1)$ \\
\hline Other & $18(14.9)$ \\
\hline \multicolumn{2}{|l|}{ Place where injury occurred ${ }^{\mathrm{a}}$} \\
\hline Home & $15(12.4)$ \\
\hline Road & $75(62.0)$ \\
\hline Work & $9(7.4)$ \\
\hline Public Area & $3(2.5)$ \\
\hline Other & $19(15.7)$ \\
\hline
\end{tabular}

Injury and acute care

ISS $^{\text {a }}$

APACHE III

Hospital LOS (days)

ICU LOS (days)

Underwent surgery ${ }^{\mathrm{a}}$

Developed a complication ${ }^{\text {a }}$

$$
\begin{gathered}
\text { Median (IQR) } \\
19(13-29) \\
41(28-53) \\
20.2(9.7-39.2) \\
2.9(1.2-7.7)
\end{gathered}
$$

\section{Frequency (\%)}

38 (31.4)

44 (36.4)

\footnotetext{
${ }^{\mathrm{a}}$ QTR data $\mathrm{n}=121$ (data not available for 2 participants due to poisoning being coded as injury but not meeting QTRs ICD-10-AM inclusions), Length of Stay (LOS)
} 
Table 4. Health Care Provider and Service Utilisation post hospital discharge

\begin{tabular}{|c|c|c|}
\hline & $\begin{array}{c}1 \text { month } \\
n=93\end{array}$ & $\begin{array}{c}6 \text { months } \\
n=88\end{array}$ \\
\hline Healthcare Provider Utilisation & \multicolumn{2}{|c|}{ Frequency (\%) } \\
\hline General Practitioner & $57(61.3)$ & $69(78.4)$ \\
\hline Pharmacist & $43(46.2)$ & $43(48.9)$ \\
\hline Physiotherapist & $30(32.3)$ & $42(47.7)$ \\
\hline Occupational Therapist & $28(30.1)$ & $26(29.5)$ \\
\hline Orthopedic Surgeon & $25(26.9)$ & $34(38.6)$ \\
\hline Hospital Based Doctor & $20(21.5)$ & $27(30.7)$ \\
\hline Nurse & $12(12.9)$ & $6(6.8)$ \\
\hline Psychologist & $6(6.5)$ & $19(21.6)$ \\
\hline Social Worker & $5(5.4)$ & $5(5.7)$ \\
\hline Speech Therapist & $5(5.4)$ & $2(2.3)$ \\
\hline Podiatrist & $2(2.2)$ & $5(5.7)$ \\
\hline Dietician/Nutritionist & $2(2.2)$ & $4(4.5)$ \\
\hline Psychiatrist & - & $4(4.5)$ \\
\hline Other Specialist & $21(22.6)$ & $24(27.3)$ \\
\hline Any Health Care Professional & $86(92.5)$ & $82(93.2)$ \\
\hline Service Utilisation & \multicolumn{2}{|c|}{ Frequency (\%) } \\
\hline Supported Accommodation & $20(21.5)$ & $13(14.8)$ \\
\hline Home Modifications & $14(15.1)$ & $11(12.5)$ \\
\hline Nursing Services & $14(15.1)$ & $9(10.2)$ \\
\hline Travel Assistance & $12(12.9)$ & $12(13.6)$ \\
\hline Assistance with meals & $7(7.5)$ & $5(5.7)$ \\
\hline Cleaning Services & $7(7.5)$ & $6(6.8)$ \\
\hline Assistance with Shopping & $6(6.5)$ & $7(7.9)$ \\
\hline Personal Care Assistant & $6(6.5)$ & $2(2.3)$ \\
\hline Any Service & 47 (50.5) & 34 (38.6) \\
\hline
\end{tabular}


Table 5. Psychosocial recovery 1 and 6 months post hospital discharge

\begin{tabular}{|c|c|c|c|}
\hline & $\begin{array}{c}1 \text { month } \\
\mathrm{n}=93\end{array}$ & $\begin{array}{c}6 \text { months } \\
\mathrm{n}=88\end{array}$ & $p$ value $^{7}$ \\
\hline Social Support & \multicolumn{2}{|c|}{ Mean (SD) } & \\
\hline MPSS total score ${ }^{a}$ & $5.6(1.1)^{*}$ & $5.3(1.3)^{*}$ & 0.032 \\
\hline Family & $5.8(1.2)$ & $5.4(1.5)$ & 0.007 \\
\hline Friends & $5.3(1.3)$ & $5.1(1.3)$ & 0.285 \\
\hline Significant Other & $5.8(1.3)^{*}$ & $5.5(1.5)^{*}$ & 0.047 \\
\hline Post Traumatic Stress & \multicolumn{2}{|c|}{ Median (IQR) / Frequency (\%) } & \\
\hline PTSD symptom severity score ${ }^{b}$ & $29.0(22.0-40.0)$ & $31.0(24.0-46.0)^{*}$ & 0.079 \\
\hline \multicolumn{4}{|l|}{ PTSD symptomatic $^{b}$} \\
\hline Yes & $18(19.4 \%)$ & $20(23.0 \%)$ & 0.791 \\
\hline \multirow[t]{2}{*}{ No } & $75(80.6 \%)$ & $67(77.0 \%)$ & \\
\hline & & (1 missing) & \\
\hline Psychological Distress & \multicolumn{2}{|c|}{ Mean (SD) / Frequency (\%) } & \\
\hline K10 total score ${ }^{\mathrm{c}}$ & $20.6(7.8)$ & $19.8(8.3)$ & 0.316 \\
\hline \multicolumn{4}{|l|}{ K10 (CRUfAD) ${ }^{\mathrm{c}}$} \\
\hline Low or no risk & $33(35.5)$ & $35(39.8)$ & $0.801^{\wedge}$ \\
\hline Medium risk & $47(50.5)$ & $42(47.7)$ & \\
\hline High risk & $13(14.0)$ & $11(12.5)$ & \\
\hline Perceived Self-Efficacy & \multicolumn{2}{|c|}{ Mean (SD) } & \\
\hline Self-Efficacy Scale ${ }^{\mathrm{d}}$ & $6.6(2.3)$ & $6.9(2.4)$ & 0.360 \\
\hline \multicolumn{4}{|l|}{ Illness Perception } \\
\hline $\mathrm{BIPQ}^{\mathrm{e}}$ & $42.5(13.7)$ & $38.3(18.0)$ & 0.002 \\
\hline
\end{tabular}

${ }^{a}$ Multidimensional Scale of Social Support (MSPSS): Score range (1-7) higher scores indicate greater perceived social support; ${ }^{\mathrm{b}}$ PTSD Checklist - Civilian Version (PCL-C): Symptom severity score range (17-85) higher scores indicate more post-traumatic stress, PTSD symptomatic: PTSD symptoms consistent with diagnosis of PTSD; ${ }^{c}$ Kessler Psychological Distress Scale: Score range (10-50) higher scores indicate greater distress, Clinical Research Unit for Anxiety and Depression, University of New South Wales (CRUfAD) cut-off scores for levels of psychological distress; ${ }^{\mathrm{d}}$ Self-Efficacy 6-Item Scale: Score range (1-10) higher score indicates a greater level of perceived self-efficacy; e Brief Illness Perception Questionnaire: Score range (0-80) higher score indicates a more threatening view of injury. ${ }^{*}$ Unable to calculate/impute score for one participant, ${ }^{*}$ comparisons made only on participants who provided data at both 1 and 6 months $(n=77-79),{ }^{\wedge}$ Bowker test of symmetry 
Table 6. Mean norm-based SF-36 scores at 1 month and 6 months ${ }^{\text {a, }}$ b

\begin{tabular}{lcccc}
\hline & Baseline & 1 month & 6months & $p$ value $^{\mathrm{c}}$ \\
\hline SF-36 Domains & & \multicolumn{2}{c}{ Mean (SD) } \\
Physical function & $53.5(7.9)$ & $30.2(13.8)$ & $39.1(14.7)$ & $<0.001$ \\
Role function-physical & $\mathrm{n} / \mathrm{a}$ & $25.8(10.4)$ & $36.2(15.3)$ & $<0.001$ \\
Bodily Pain & $\mathrm{n} / \mathrm{a}$ & $35.5(11.4)$ & $42.4(11.9)$ & $<0.001$ \\
General health & $\mathrm{n} / \mathrm{a}$ & $45.6(9.7)$ & $45.3(11.1)$ & 0.864 \\
Vitality & $\mathrm{n} / \mathrm{a}$ & $40.9(10.1)$ & $45.8(11.0)$ & $<0.001$ \\
Social function & $\mathrm{n} / \mathrm{a}$ & $32.2(13.8)$ & $40.2(13.3)$ & $<0.001$ \\
Role function-emotional & $\mathrm{n} / \mathrm{a}$ & $30.9(22.2)$ & $37.4(18.1)$ & 0.065 \\
Mental health & $\mathrm{n} / \mathrm{a}$ & $43.1(12.1)$ & $43.3(13.0)$ & 0.210 \\
Physical component summary & $\mathrm{n} / \mathrm{a}$ & $32.7(10.4)$ & $40.9(13.2)$ & $<0.001$ \\
Mental component summary & $\mathrm{n} / \mathrm{a}$ & $40.6(15.7)$ & $42.6(14.0)$ & 0.147
\end{tabular}

${ }^{a}$ Norm-based scores for domains and summary score are calculated from raw scores using Australian population norms (SAHOS); scores are interpreted with a population mean of 50 and standard deviation of $10,{ }^{b}$ Due to missing data $n=88-93$ at 1 month and $n=86-88$ at 6 month follow-up, ${ }^{\mathrm{c}}$ Wilcoxon Match Paired test $(1$ month -6 months) ${ }^{\mathrm{n} / \mathrm{a}}$ Not assessed at baseline 


\begin{tabular}{|c|c|c|c|}
\hline $\begin{array}{l}\text { Pre-Injury/Injury } \\
\text { Characteristics }\end{array}$ & Hospital Care & $\begin{array}{l}\text { Post-Discharge } \\
\text { Factors }\end{array}$ & Outcomes \\
\hline $\begin{array}{l}\text { - Demography } \\
\text { - Socio-economic } \\
\text { status } \\
\text { - Pre-injury status } \\
\text { - Injury }\end{array}$ & $\begin{array}{l}\text { - Length of stay } \\
\text { (ICU, hospital) } \\
\text { - ICU liaison } \\
\text { services } \\
\text { - Adverse events }\end{array}$ & $\begin{array}{ll}\text { - } & \text { Social support } \\
\text { - } & \text { Psychological } \\
\text { status } \\
\text { - Health service } \\
\text { use }\end{array}$ & $\begin{array}{l}\text { - Health status } \\
\text { - Economic } \\
\text { status }\end{array}$ \\
\hline
\end{tabular}

Figure 1: Potential Factors Influencing Outcomes in Critically Injured Patients 


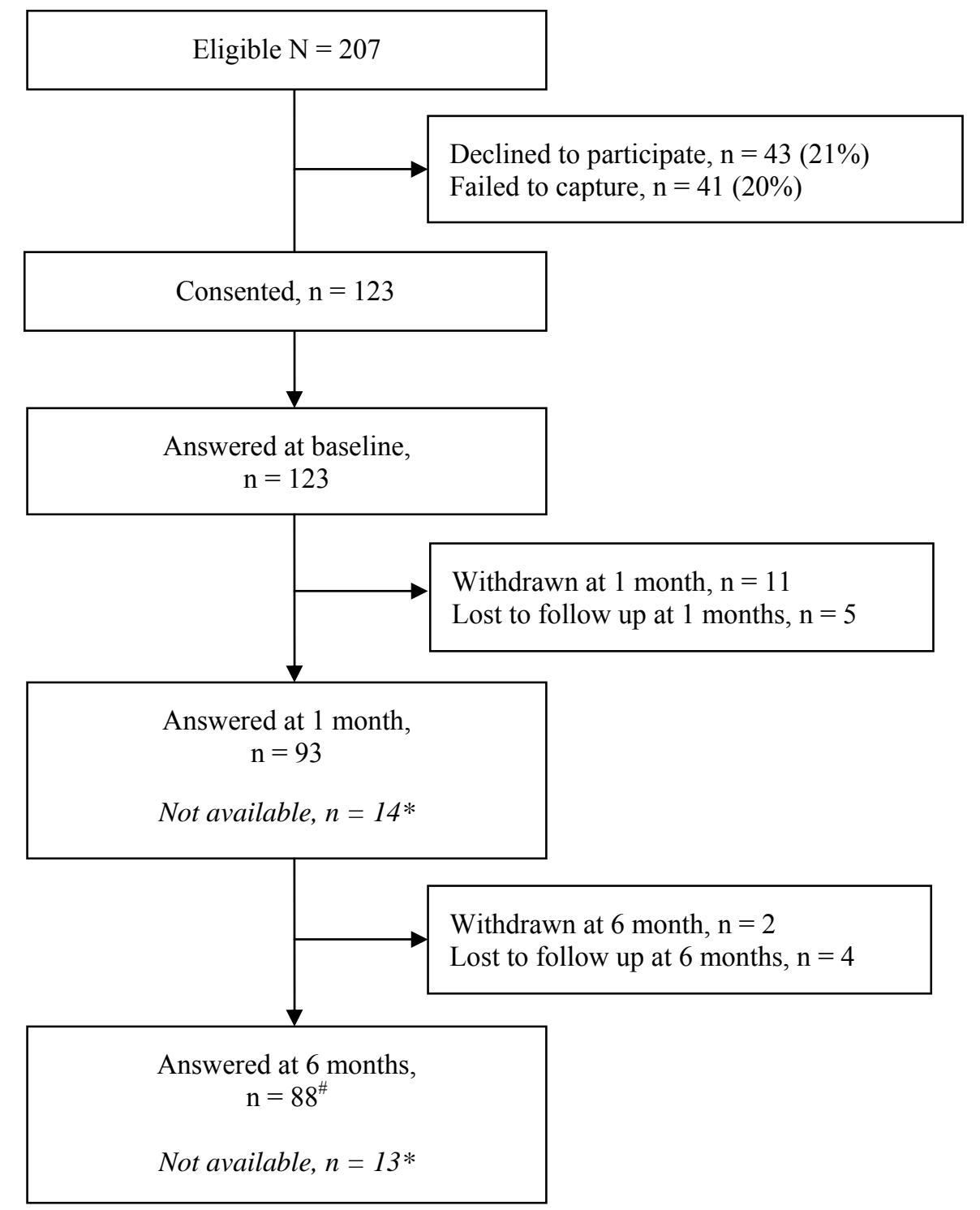

* Participant indicated they were unable to provide data for this time point but agreed to be contacted at subsequent data collection points.

${ }^{*}$ Of the 88 participants followed up at 6 months $10 \%(n=9)$ did not provide data at 1 month (indicated they were not available).

\section{Figure 2: Participant flow through study}




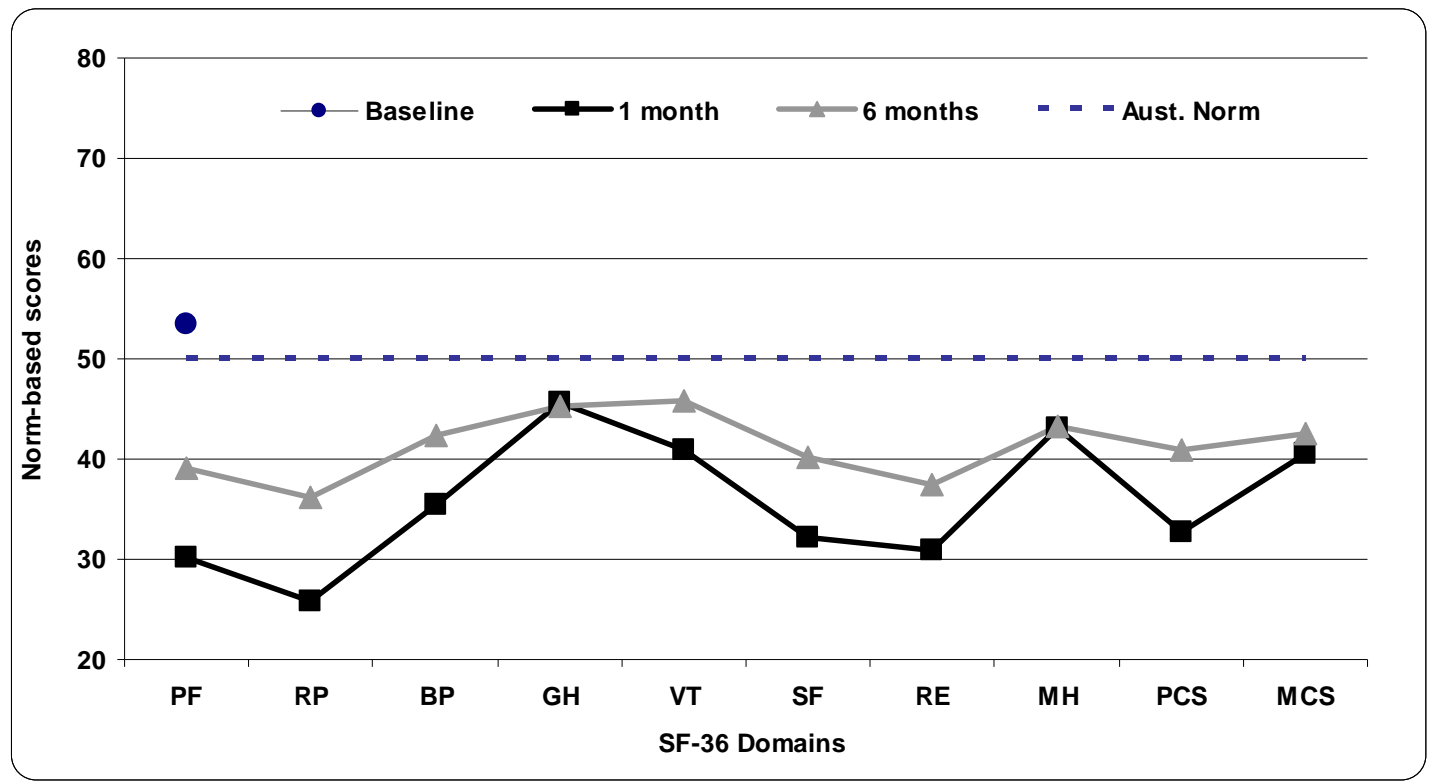

Figure 3. Mean norm-based SF-36 scores by time point and compared with Australian norms 